\title{
Prevalence and Risk Factors of Neuropsychological Issues Following Acute Mild Traumatic Brain Injury
}

\author{
Ramesh Kannan ${ }^{1}$, Shanthi Kannan², Stalin P. ${ }^{3}$ \\ 1Department of Neurology, Pondicherry Institute of Medical Sciences, Pondicherry, India. ${ }^{2}$ Department of Paediatrics, \\ Pondicherry Institute of Medical Sciences, Pondicherry, India. ${ }^{3}$ Department of Community Medicine, Pondicherry \\ Institute of Medical Sciences, Pondicherry, India.
}

ABSTRACT

\section{BACKGROUND}

Traumatic brain injury (TBI) is one of the major causes of neurological disability in India ${ }^{1}, 80-90 \%$ of TBIs are mild ${ }^{2,3}$. Mild traumatic brain injury (mTBI) participants may present with post concussive symptoms especially deficits in cognition which is commonly ignored. Unidentified cognitive deficits in the acute phase of mTBI may result in long term functional problems and poor quality of life. Aim of the present study is to determine the prevalence and risk factors of neuropsychological issues in mild traumatic brain injury.

\section{METHODS}

Ninety persons with mild traumatic brain injury admitted to the emergency unit of neurosciences in a Chennai based tertiary care hospital aged between 20 and 60 years with Glasgow Coma Scale Score of 13-15 were assessed with PGI battery of brain dysfunctions within 48 hours of admission. Impairment in memory, verbal intelligence, performance intelligence, visual acuity and visuospatial functions were assessed using the battery. Cognitive dysfunction was evaluated using dysfunction rating scale scores in each test.

\section{RESULTS}

Data were analysed using IBM SPSS Version 21. Cognitive dysfunction was found to be higher in memory such as delayed recall, visual and verbal retention of new information, mental balance and constructional ability. Male participants (30\%) between 50-60 years (70\%) with lower educational qualification (44.4\%) had severe cognitive impairment compared to others. Housewives (57.1\%) had severe dysfunction in learning and retaining new information. Abnormality in CT report $(35.9 \%)$ was found to have significant effect on visual retention.

\section{CONCLUSIONS}

There is significant cognitive impairment in various domains of memory and constructional abilities in the acute phase of single mTBI. Factors such as age, gender, years of education, occupation and structural abnormality were found to be risk factors for individual vulnerabilities. Younger age, higher educational qualifications and good occupational skills with uncomplicated CT reports were found to play protective roles as cognitive reserves in preventing cognitive dysfunction after traumatic brain injury.

\section{KEY WORDS}

mTBI, Cognitive Dysfunction, Memory Impairment, PGI BBD, Cognitive Reserve

\author{
Corresponding Author: \\ Shanthi Kannan, \\ Department of Paediatrics, \\ Pondicherry Institute of Medical Sciences, \\ Pondicherry-605014, India. \\ E-mail: shan_kannan@yahoo.co.in
}

DOI: $10.14260 /$ jemds/2019/751

Financial or Other Competing Interests: None.

How to Cite This Article:

Kannan R, Kannan S, Stalin P. Prevalence and risk factors of neuropsychological issues following acute mild traumatic brain injury. J. Evolution Med. Dent. Sci. 2019;8(46):3469-3473, DOI: 


\section{BACKGROUND}

Mild traumatic brain injury, one of the common types of TBI is defined by American Congress of Rehabilitation Medicine as mild injury to the head resulting in loss of consciousness less than thirty minutes with a loss of memory immediately before or after the accident and no longer than twenty-four hours, or alteration in mental state at the time of accident such as disorientation, confusion, with Glasgow Coma Scale Score between 13-15, and post-traumatic amnesia of not more than twenty-four hours followed by impairment in cognitive function. ${ }^{4}$ Cognitive impairment has been reported in many domains such as attention, learning and memory especially immediate recall, short-delayed recall, longdelayed recall, executive functions and processing speed.5-8 Repeated mTBIs can result in persistent post concussive symptoms as a single concussion is known to cause disruption in neurological mechanisms leading to cognitive impairment.9-11 The acute symptoms that may follow mild traumatic brain injury are often categorized according to three domains such as physical, behavioural/ emotional and cognitive. Common Symptoms are clumsiness, fatigue, confusion, nausea, blurred vision and headache. CT and MRI usually fail to detect evidence of structural brain abnormalities in mild traumatic brain injury. In most cases, participants who experience mild traumatic brain injury will recover fully, typically within days to months. However, $15 \%$ of mTBIs have been reported to have persistent disabling cognitive problems. ${ }^{12,13}$ There may be reduced functional ability, emotional distress, return to work may be delayed as a consequence. Post-concussion syndrome is determined by the symptoms persisting beyond the typical recovery period of three months. Mild concussions are associated with sequelae which includes memory problems, dizziness, depression, anxiety, anger and tiredness. It is reported that $80-100 \%$ of mTBIs complain symptoms like headache, slowed thinking, impaired attention and memory. ${ }^{14}$ About $40 \%$ have persistent symptoms for three to six months post injury. They require objective neuropsychological assessment and neuroimaging to identify the contributing factors. ${ }^{15}$ Very few studies have focused on evaluating the cognitive impairment and the associated risk factors in the acute phase of mTBI. Hence, aim of the current study was to determine the prevalence and risk factors of neuropsychological issues in mild traumatic brain injury.

\section{METHODS}

The study was conducted in a tertiary care medical and research institute in Chennai. Ninety persons with first episode of mTBI admitted to the emergency unit of Neurosciences constituted as the sample for the study. Sample size was taken based on the convenience of the study. Written consent and demographic data were obtained from all the participants. They were assessed by qualified and trained neuropsychologist bedside during the first 24 hours of admission, called the acute phase of mTBI with PGI battery of brain dysfunctions. ${ }^{16}$ Participants were diagnosed on the basis of diagnostic protocol defined by the Mild Traumatic Brain Injury Committee of the American Congress of
Rehabilitation Medicine. ${ }^{4}$ Participants with Glasgow Coma Score (GCS) of 13-15,17 between 20-60 years of age with loss of consciousness less than 30 minutes following injury with alteration of mental state at the time of incident were included for the study. Participants with a known history of psychiatry problems, diabetes mellitus, cardiac illness, previous head injury, epilepsy and any other chronic illnesses/neurological disorders were excluded from the study. This study was approved by the Institutional ethics committee.

Cognitive assessment was done with PGI Battery of Brain Dysfunctions which is used to evaluate the extent of dysfunction in ten domains of memory, verbal and performance intelligence, visual acuity and perceptuo-motor skills. ${ }^{16}$ It took approximately 90-120 minutes for complete administration. Dysfunction rating scores (DRS) were calculated based on the norms given in each subtest. Memory subtests assesses 10 different areas of Memory namely Remote memory, Recent memory, Mental Balance, Attention and Concentration, Delayed Recall, Immediate Recall (Sentence Reproduction), Verbal retention of similar pairs, Verbal retention of dissimilar pairs, Visual retention and Recognition. Verbal Adult Intelligence Scale assesses the verbal ability of the person stressing on power and capacity. It consists of four subtests i.e. Information, Arithmetic, Digit Span and Comprehension. Revised Bhatia's Short Battery of Performance test of Intelligence for adults consists of two subtests namely Koh's block design test and Alexander's pass along test to assess the performance intelligence of the individuals. It focuses on speed, accuracy and efficiency. Nahor Benson Test measures perceptuo-motor functioning of the right hemisphere and related to parieto occipital lobe. Bender Visual Motor Gestalt Test evaluates visual motor functioning and organicity in mental functions among head injured individuals. ${ }^{16}$

\section{Statistical Analysis}

Data was analyzed using the International Business Machines Statistical Package for the Social Sciences (IBM SPSS), version 21. Proportions were calculated. Chi-square tests were used to compare the proportion between different categories. Significance level was set at 0.05 .

\section{RESULTS}

A total of ninety participants underwent neuropsychological assessment at acute phase of mTBI. Information on sociodemographic characteristics of the sample is summarized in Table. 1 . There were mainly men $(66.7 \%)$ between $20-30$ years $(57.8 \%)$ with professional degree $(41.1 \%)$. Majority of them were working as software engineers (52.2\%). Many participants had normal CT findings (56.7\%). Cognitive performance of the participants is presented in Table 2 . Maximum number of participants assessed had mild dysfunction in memory especially in domains such as delayed recall $(22.2 \%)$, visual retention $(23.3 \%)$ and constructional abilities (Koh's Block design test of Performance Intelligence test, $17.8 \%$ ). Severe dysfunction was found in certain domains of memory especially in mental balance $(14.4 \%)$ and verbal retention for dissimilar pairs (25.6\%). Less than $10 \%$ 
of the individuals with mTBI had mild dysfunction in other areas of cognition assessed in acute phase of injury.

The relationship between the demographic differences in cognitive dysfunction are shown in Table 3. There were significant demographic differences only in certain areas of memory dysfunction. Mostly men $(\mathrm{p}<.05)$ between 50-60 years had severe dysfunction in visual retention of dissimilar pairs $(\mathrm{p}<.05)$ and mild dysfunction in verbal retention $(p<.05)$ compared to other age groups. Mild dysfunction in verbal retention $(\mathrm{p}<.05)$ and mental balance $(\mathrm{p}<.001)$ was highly prevalent in persons who stopped with school education compared to others with higher educational levels. Mostly housewives were found to have severe dysfunction in verbal retention of dissimilar pairs $(p<.05)$ and mental balance $(\mathrm{p}<.05)$ compared to other occupational groups. Mild dysfunction in visual retention was found to be high in persons with abnormal CT report compared to those with normal report $(\mathrm{p}<.05)$. There were no statistically significant differences in cognitive dysfunction in other domains based on their demographics.

\begin{tabular}{|c|c|c|}
\hline Demographic Details & $\mathbf{N}$ & $\%$ \\
\hline \multicolumn{3}{|c|}{ Age (in Years) } \\
\hline $20-30$ & 52 & 57.8 \\
\hline $31-40$ & 18 & 20.0 \\
\hline $41-50$ & 10 & 11.1 \\
\hline $51-60$ & 10 & 11.1 \\
\hline \multicolumn{3}{|c|}{ Gender } \\
\hline Male & 60 & 66.7 \\
\hline Female & 30 & 33.3 \\
\hline \multicolumn{3}{|c|}{ Education } \\
\hline School & 18 & 20.0 \\
\hline Undergraduate & 20 & 22.2 \\
\hline Postgraduate & 15 & 16.7 \\
\hline Professional degree & 37 & 41.1 \\
\hline \multicolumn{3}{|c|}{ Occupation } \\
\hline Software engineer & 47 & 52.2 \\
\hline Teacher & 5 & 5.6 \\
\hline Clerk & 28 & 31.1 \\
\hline Student & 3 & 3.3 \\
\hline Housewife & 7 & 7.8 \\
\hline \multicolumn{3}{|c|}{ CT Report } \\
\hline Normal & 51 & 56.7 \\
\hline Abnormal & 39 & 43.3 \\
\hline Total & 90 & 100.0 \\
\hline \multicolumn{3}{|c|}{$\begin{array}{l}\text { Table 1. Socio-Demographic Characteristics of } \\
\text { the Study Participants }(n=90)\end{array}$} \\
\hline
\end{tabular}

\begin{tabular}{|c|c|c|}
\hline Subtest & $\begin{array}{l}\text { Mild Dysfunction } \\
\text { N (\%) } \\
\end{array}$ & \begin{tabular}{|c|}
$\begin{array}{c}\text { Severe Dysfunction } \\
\text { N (\%) }\end{array}$ \\
\end{tabular} \\
\hline \multicolumn{3}{|c|}{ Memory } \\
\hline Remote memory & $2(2.2)$ & $2(2.2)$ \\
\hline Recent memory & $8(8.9)$ & $8(8.9)$ \\
\hline Mental Balance & $11(12.2)$ & $13(14.4)$ \\
\hline Attn \&Conc. & $9(10)$ & $10(11.1)$ \\
\hline Delayed Recall & $20(22.2)$ & $6(6.7)$ \\
\hline Immediate Recall & $8(8.9)$ & $9(10)$ \\
\hline VRSP & 13(14.4) & $8(8.9)$ \\
\hline VRDP & $13(14.4)$ & $23(25.6)$ \\
\hline Visual Retention & $21(23.3)$ & $7(7.8)$ \\
\hline Recognition & $9(10)$ & $5(5.6)$ \\
\hline \multicolumn{3}{|l|}{ Verbal Intelligence Test } \\
\hline General Intelligence & $9(10)$ & - \\
\hline Comprehension & $9(10)$ & $1(1.1)$ \\
\hline Arithmetic & $2(2.2)$ & - \\
\hline Digit Span & $4(4.4)$ & - \\
\hline Verbal IQ & $3(3.3)$ & - \\
\hline \multicolumn{3}{|c|}{ Performance Intelligence Test } \\
\hline Block design test & $16(17.8)$ & $4(4.4)$ \\
\hline Pass along test & $6(6.7)$ & $1(1.1)$ \\
\hline Performance IQ & $7(7.8)$ & - \\
\hline Nahor Benson Test & $5(5.6)$ & - \\
\hline BVMG & $9(10)$ & - \\
\hline \multicolumn{3}{|c|}{$\begin{array}{c}\text { Table 2. Prevalence of Cognitive Dysfunction among } \\
\text { the Study Participants }(n=90)\end{array}$} \\
\hline
\end{tabular}

\begin{tabular}{|c|c|c|c|c|c|c|}
\hline \multirow[b]{2}{*}{ 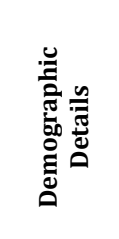 } & \multicolumn{2}{|c|}{$\begin{array}{c}\text { Verbal Retention } \\
\text { for Dissimilar Pairs }\end{array}$} & \multicolumn{2}{|c|}{ Visual Retention } & \multicolumn{2}{|c|}{ Mental Balance } \\
\hline & 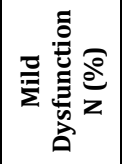 & 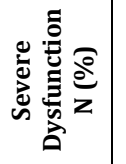 & 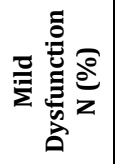 & 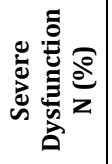 & 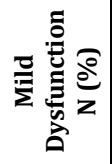 & 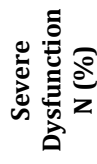 \\
\hline \multicolumn{7}{|c|}{ Age } \\
\hline $20-30$ yrs. & $7(13.5)$ & (15.4) & 13 & $3(5.8)$ & $5(c$ & 13 \\
\hline $31-40$ & & & & & & \\
\hline $41-5$ & & & & )) & & \\
\hline $51-60$ & & $7(70)^{*}$ & & 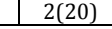 & & \\
\hline \multicolumn{7}{|c|}{ Gender } \\
\hline Male & $0)$ & $0)^{*}$ & $12(20)$ & 30) & & $0)$ \\
\hline Female & & $5(16.7)$ & $1(3.3)$ & $5(16.7)$ & 4( & $1(3.3)$ \\
\hline \multicolumn{7}{|c|}{ Education } \\
\hline Schoo & 8) & $7(38.9)$ & $7(38.9)^{*}$ & 5) & $8(44$ & $2(11.1)$ \\
\hline UG & 15) & $7(35)$ & & $4(20)$ & $1(5)$ & $6(30)$ \\
\hline PG & & $6(40)^{*}$ & & $0(0)$ & 0 & 6.7) \\
\hline Prof. degree & $0.8)$ & $3(8.1)$ & $6(16.2)$ & $2(5.4)$ & $2(5.4)$ & $1(2.7)$ \\
\hline \multicolumn{7}{|c|}{ Occupation } \\
\hline Soft. Eng. & 4) & 9(19.1) & 9) & $4.3)$ & 4) & 6.4) \\
\hline Teacher & $1(20)$ & 20) & & & & 0) \\
\hline lerk & 1) & 2.1) & & ) & & \\
\hline ident & & & & $0(0)$ & & $0(0)$ \\
\hline Housewife & (0) & $4(57.1)^{*}$ & $2(28.6)$ & $0(0)$ & $3(42.9)^{*}$ & $0(0)$ \\
\hline \multicolumn{7}{|c|}{ CT Report } \\
\hline rmal & & 21.6) & & $4(7.8)$ & & \\
\hline Abnormal & $6(15.4)$ & $12(30.18)$ & $14(35.9)^{*}$ & $3(7.7)$ & $5(12.8)$ & $8(20.5)$ \\
\hline \multicolumn{7}{|c|}{$\begin{array}{l}\text { Table 3. Relationship between the Demographic Factors and } \\
\text { Cognitive Dysfunction among the Study Participants }(n=90)\end{array}$} \\
\hline & & & & & & \\
\hline
\end{tabular}

\section{DISCUSSION}

The present study was conducted to investigate the prevalence of cognitive dysfunction following mTBI and protective factors that play as a buffer in the prevention of cognitive impairment in the acute phase. Most of the participants with mTBI were young men $(66.7 \%)$ between 20-30 years of age (57.8\%) working as engineering professionals(52.2\%) with higher academic achievement (41.1\%). $56.7 \%$ of them had normal CT findings. The findings of our study revealed high cognitive dysfunction in specific domains of memory and constructional abilities in the acute phase of mTBI. Severe dysfunction was high in verbal retention of dissimilar pairs which represents learning and retention of new information (25.6\%). Mild dysfunction was found to be high in delayed recall (22.2\%) and visual retention $(23.3 \%)$ in memory subtest and constructional abilities $(17.8 \%)$ of performance intelligence test. Only a small percentage of individuals with mTBI had dysfunction in other areas of cognition.

Persons aged between 50-60 years performed much worse in memory subtests compared to other age groups. They had severe dysfunction in verbal retention of dissimilar pairs $\left(70 \%, X^{2}=16.467, \mathrm{df}=6, \mathrm{p}<.05\right)$ and mild dysfunction in visual retention $\left(60 \%, X^{2}=19.713, d f=6, p<.05\right)$ compared to others which indicates that age has severe impact on memory post injury. Studies support the fact that aging is associated with deficiencies in retrieval of information and is more pronounced when the response is new and restricted.18,19 In acute mTBI, aging is reported to be associated with poor neural recovery. ${ }^{20}$ Gender was also found to significantly affect cognitive performance post mTBI. Men had severe deficits in acquiring and storing new information than women $\left(30 \%, \mathrm{X}^{2}=8.236, \mathrm{df}=2, \mathrm{p}<.05\right)$. Literature reviews 
support the findings of our study that women outperform men in memory subtests. Gender was reported to be significantly associated with performance in memory and executive functions. ${ }^{21,22}$ There were no significant gender differences found in other cognitive domains.

Our findings also revealed that participants who had less number of years of education had more deficits compared to others. $38.9 \%$ of them had mild dysfunction in visual retention $\left(X^{2}=16.087, \mathrm{df}=6, \mathrm{p}<.05\right)$ and $44.4 \%\left(\mathrm{X}^{2}=31.932\right.$, $\mathrm{df}=6, \mathrm{p}<.001$ ) in mental balance. These findings indicate that education plays a supportive role in protecting cognitive performance after TBI. Participants with higher educational qualification and a greater number of years of education performed better in neuropsychological tests. Education prevents the deleterious effects of concussion. Earlier studies support the fact that number of years of education is associated with better cognitive performance in domains like memory, learning and executive functions. ${ }^{23,24}$

Based on their occupation, housewives were found to be more affected in cognitive performance following mTBI compared to those in other professions. $57.1 \%$ of them exhibited severe dysfunction in learning and storing new information $\left(\mathrm{X}^{2}=20.063, \mathrm{df}=8, \mathrm{p}<.05\right)$ and $42.9 \%$ had mild deficit in mental balance $\left(X^{2}=21.255, d f=8, p<.05\right)$. High premorbid intelligence, higher education and good occupational skills serve as cognitive reserves for better cognitive outcome following TBI. Participants with reduced cognitive reserves were reported to be 4.14 times more likely to suffer from cognitive deficits. ${ }^{25,26}$

Cognitive impairment was found to be higher in participants with complicated CT report compared to normal uncomplicated report. ${ }^{27} 35.9 \%$ of our participants with complicated CT reports showed mild cognitive dysfunction in visual retention compared to those with normal CT findings $\left(\mathrm{X}^{2}=6.212, \mathrm{df}=2, \mathrm{p}<.05\right)$ indicating that structural abnormality following mTBI impairs memory. Studies report that changes in white matter integrity in splenium of corpus callosum and cingulum $^{28}$ and gray matter morphological changes are associated with impairment in selective and divided attention and working memory in the acute phase of mTBI. ${ }^{29}$

We did not find any demographic differences in other areas of cognitive deficit like attention and concentration, recent and remote memory, immediate recall and recognition, visual acuity, visuospatial skills, perceptuomotor ability, information processing speed and verbal intelligence subtests in the acute phase of mTBI.

\section{Implications}

Many studies and literature reviews have been conducted to understand post concussive symptoms, associated factors such as LOC, previous TBIs and importance of management strategies in the chronic phase. ${ }^{30-33}$ However, none of the studies in India have focused on the demographic determinants and structural factors associated with specific cognitive dysfunction in the acute phase of mTBI. Though mTBIs constitute $70-90 \%$ of TBIs, due to negligence, many individuals with mTBI do not report to the emergency, not admitted for detailed investigation or not evaluated by neuro team. Since the sampling can be done only with hospitalized participants, the actual estimation of incidence and prevalence of cognitive impairment in mTBI is difficult. ${ }^{34}$ This study is first of its kind performed on mTBI participants to identify the cognitive impairment and associated demographic determinants, reveals the protective factors, and thus would help in planning suitable cognitive intervention strategies.

Limitations: We did not include individuals with previous history of psychiatric illness, seizure or other neurological disorder and repetitive TBI which would have influenced cognitive performance.

\section{CONCLUSIONS}

There is significant cognitive impairment in various domains of memory and constructional abilities in the acute phase of single mTBI. Factors such as age, gender, years of education, occupation and structural abnormality were found to be risk factors for individual vulnerabilities. Younger age, higher educational qualifications and good occupational skills with uncomplicated CT reports were found to play protective roles as cognitive reserves in preventing cognitive dysfunction after traumatic brain injury.

\section{REFERENCES}

[1] Das A, Botticello AL, Wylie GR, et al. Neurologic disability: a hidden epidemic for India. Neurology 2012;79(21):2146-7.

[2] Amaranath JE, Ramanan M, Reagh J, et al. Epidemiology of traumatic head injury from a major paediatric trauma centre in New South Wales, Australia. ANZ J Surg 2014;84(6):424-8.

[3] Vos PE, Alekseenko Y, Battistin L, et al. Mild traumatic brain injury. Eur J Neurol 2012;19(2):191-8.

[4] Mild Traumatic Brain Injury Committee of the Head Injury Interdisciplinary Special Interest Group of the American Congress of Rehabilitation Medicine. Definition of mild traumatic brain injury. Journal of Head Trauma Rehabilitation 1993;8(3):86-7.

[5] McCauley RL, Wilde EA, Barnes A, et al. Patterns of early emotional and neuropsychological sequelae after mild traumatic brain injury. J Neurotrauma 2014;31(10):91425.

[6] Sivak S, Bittšansky M, Grossmann J, et al. Clinical correlations of proton magnetic resonance spectroscopy findings in acute phase after mild traumatic brain injury. Brain Inj 2014;28(3):341-6.

[7] Barker-Collo S, Jones K, Theadom A, et al. Neuropsychological outcome and its correlates in the first year after adult mild traumatic brain injury: a population-based New Zealand study. Brain Inj 2015;29(13-14):1604-16.

[8] Rabinowitz AR, Levin HS. Cognitive sequelae of traumatic brain injury. Psychiatr Clin North Am 2014;37(1):1-11.

[9] Xiong K, Zhu Y, Zhang Y, et al. White matter integrity and cognition in mild traumatic brain injury following motor vehicle accident. Brain Research 2014;1591(1):86-92.

[10] Belanger HG, Spiegel E, Vanderploeg RD. Neuropsychological performance following a history of 
multiple self-reported concussions: a meta-analysis. J Int Neuropsychol Soc 2010;16(2):262-7.

[11] Stein MB, Ursano RJ, Campbell-Sills L, et al. Prognostic indicators of persistent post-concussive symptoms after deployment-related mild traumatic brain injury: a prospective longitudinal study in U.S. Army Soldiers. J Neurotrauma 2016;33(23):2125-32.

[12] Spinos P, Sakellaropoulos G, Georgiopoulos M, et al. Postconcussion syndrome after mild traumatic brain injury in Western Greece. J Trauma 2010;69(4):789-94.

[13] Sterr A, Herron KA, Hayward C, et al. Are mild head injuries as mild as we think? Neurobehavioral concomitants of chronic post-concussion syndrome. BMC Neurology 2006;6:7.

[14] McMillan TM, Herbert CM. Further recovery in a potential treatment withdrawal case 10 years after brain injury. Brain Inj 2004;18(9):935-40.

[15] McCullagh S, Oucherlony D, Protzner A, et al. Prediction of neuropsychiatric outcome following mild trauma brain injury: an examination of the Glasgow Coma Scale. Brain Inj 2001;15(6):489-97.

[16] Pershad D, Verma SK. Hand-book of PGI Battery of Brain Dysfunction (PGI-BBD). $1^{\text {st }}$ edn. Agra, India: National Psychological Corp., 1990.

[17] Kristman VL, Borg J, Godbolt AK, et al. Methodological issues and research recommendations for prognosis after mild traumatic brain injury: results of the International Collaboration on Mild Traumatic Brain Injury Prognosis. Arch Phys Med Rehabil 2014;95(Suppl 3):S265-77.

[18] Mortensen L, Meyer AS, Humphreys GW. Age-related effects on speech production: a review. Lang Cogn Proc 2006;21(1-3):238-90.

[19] Paolieri D, Marful A, Morales L, et al. The modulating effect of education on semantic interference during healthy aging. PLoS One 2018;13(1):e0191656.

[20] Cho Y, Latour LL, Kim H, et al. Older age results in differential gene expression after mild traumatic brain injury and is linked to imaging differences at acute follow-up. Front Aging Neurosci 2016;8:168.

[21] Ratcliff JJ, Greenspan AI, Goldstein FC, et al. Gender and traumatic brain injury: Do the sexes fare differently? Brain Inj 2007;21(10):1023-30.

[22] Moore DW, Ashman TA, Cantor JB, et al. Does gender influence cognitive outcome after traumatic brain injury? Neuropsychol Rehabil 2010;20(3):340-54.
[23] Sumowski JF, Chiaravalloti N, Krch D, et al. Education attenuates the negative impact of traumatic brain injury on cognitive status. Arch Phys Med Rehabil 2013;94(12):2562-4.

[24] Leary JB, Kim GY, Bradley CL, et al. The association of cognitive reserve in chronic-phase functional and neuropsychological outcomes following traumatic brain injury. J Head Trauma Rehabil 2018;33(1):E28-E35.

[25] Mathias LJ, Wheaton P. Contribution of brain or biological reserve and cognitive or neural reserve to outcome after TBI: a meta-analysis (prior to 2015). Neurosci Biobehav Rev 2015;55:573-93.

[26] Oldenburg C, Lundin A, Edman G, et al. Cognitive reserve and persistent post-concussion symptoms-a prospective mild traumatic brain injury (mTBI) cohort study. Brain Inj 2016;30(2):146-55.

[27] Borgaro SR, Prigatano GP, Kwasnica C, et al. Cognitive and affective sequelae in complicated and uncomplicated mild traumatic brain injury. Brain Inj 2003;17(3):18998.

[28] Veeramuthu V, Narayanan V, Kuo TL, et al. Diffusion tensor imaging parameters in mild traumatic brain injury and its correlation with early neuropsychological impairment: a longitudinal study. J Neurotrauma 2015;32(19):1497-509.

[29] Dall'Acqua P, Johannes S, Mica L, et al. Prefrontal cortical thickening after mild traumatic brain injury: a one year MRI study. J Neurotrauma 2017;34(23):3270-9.

[30] Munivenkatappa A, Devi BI, Shukla DP, et al. A preliminary study of natural history of mild traumatic brain injury by using multidimensional approach. Indian J Med Res 2017;146(1):78-82.

[31] Castro S, Damin AE, Porto CS, et al. The abbreviated form of the Brief Cognitive Battery in the diagnosis of dementia in Alzheimer's disease. Dement Neuropsychol 2009;3(4):327-31.

[32] Miotto EC, Cinalli FZ, Serrao VT, et al. Cognitive deficits in patients with mild to moderate traumatic brain injury. Arquiv Neuropsiq 2010;68(6):862-8.

[33] Fonseca RP, Zimmermann N, Cotrena C, et al. Neuropsychological assessment of executive functions in traumatic brain injury: hot and cold components. Psychol Neurosci 2012;5(2):183-90.

[34] Shukla D, Devi BI. Mild traumatic brain injuries in adults. J Neurosci Rural Pract 2010;1(2):82-8. 